\title{
Social Work Students Using Technology to Promote Social Justice: From Student to Advocate
}

\author{
Betty Blackmon, MSW, JD \\ Associate Professor \\ University of Missouri School of Social Work \\ Kansas City, Missouri 64110, USA
}

\begin{abstract}
Social workers have maintained that social justice is one of the most important tenets of their profession. Promoting social justice is the main differentiating factor between social work and other professions. Social workers struggle over the best ways to train students to promote social justice issues and techniques to fight effectively for social justice. Methods to train social workers to advocate for social justice vary and so do the results. Engaging in social justice practice requires the addition of technology and students need to learn the advantages of technology integration into community change efforts. This article describes the integration of technology into the assignments of three community practice courses where students became advocates for change.
\end{abstract}

Keywords: Social Work, Social Work Education, technology and Social Justice, social justice, NASW, community practice, macro change, technology and Social Change

\section{Introduction}

President Barack Obama, a former community organizer, was familiar with traditional social change techniques, such as mass letter writing, door to door canvassing, and public rallies. Campaign history was made when Barak Obama merged older social change techniques with the modern tools of technology. The successful use of technologies such as Facebook, e-broadcasts, e-mail, blogs, and other such media techniques were integrated into "good old fashion" organizing strategies, the incorporation of these mediums his political campaign resulted in a win. Initially, Obama's past role as a community organizer was minimized by his opponents, but the recognition of the success of these strategies came much too late for President Barack Obama's opponents. The results of his campaign strategy are instructive to current and future social workers who face the daunting tasks of alleviating poverty, racism, oppression and discrimination as mandated by their profession (NASW, 2015).

Social workers have maintained that social justice is one of the most important tenets of the profession. Challenging social injustices and fighting for justice are core values held by the profession of social work (NASW, 2015).The Council on Social Work Education and the National Association of Social Workers uniformly agree that it is the duty and responsibility of all social workers to promote social justice and social change on behalf of the clients (CSWE EPAS, 2015\& NASW, 2015).

The form of advocacy implemented in everyday practice may vary from social worker to social worker. This variance includes change efforts ranging from activities such as advocating for new or expanded services often called "case advocacy", or cause change efforts such as getting Medicaid to pay for psychotropic drugs (Abramovitz, M>\& Sherraden, M.S., 2016). Social workers engaging in practice on these levels such as those used by generalist practitioners involve complex strategies. For example, empowering communities to address significant problem require varied activities such as those discussed in Krist-Ashman's macro social environment textbook (Krist-Ashman \& Hull, 2012 pg. 460).

The need for social workers trained in social justice advocacy that incorporating enhancement of current strategies along with the integration of technology is on the rise. As a result, macro strategies to address social problems that are decimating the vulnerable and at-risk populations are in of an "upgrade". A technological upgrade will create new and formidable strategies when used to address conditions such as racism and discrimination. 
Alleviating and reducing racism, discrimination and conditions such as poverty issues require multiple skill levels such as assessing these conditions impact, macro change strategies, mobilizing and empowering helpers and the assisted, building and sustaining collaborations. These skills are required, because of the difficulty in dismantling systems such as those that are embedded in institutions and society. The social work's profession's mandate to decrease or diminish the injustices occurring in the lives of their clients and other vulnerable and at-risk populations remains. However, reducing the impact caused by this injustice is not evident in the activities of current day social work practitioners and educators. The need remains to educate social work students to engage in macro practice as a part of their a purpose.

Social justice activitiesare needed to dismantle racism and the other isms" illustrates the theme of "practice with a purpose". Engaging in this practice is not effective if practitioners and and educators are not part of using and teaching macro knowledge and effective interventions. Macro changeinterventions that are effective and evidence are necessary if we are to implement the recommendations espoused by the profession at the 2005 Social Work Congress and the NASW Racism policy statement (NASW, 2006).

Additionally, implementing the pronouncements made by the National Association of Social Work and others in the profession require more efforts directed toward educating social workers about social justice strategies combined with technology. This combination will enable the social worker to reach beyond their immediate environments and reach out to the world for the purpose of advocacy, educating, and mobilizing. This global expansion enables social workers to adopt effective strategies from around the world utilizing all online sources that are available. This adoption requires that they reach out and through open source material quip others to empower and mobilize others using the knowledge and skills of social work.

Upgrading and increasing the technology skills of social workers and social work educators is necessary to accomplish their mission. Fulfilling the social work mission require social workers to learn about the research that establishes the effectiveness of online education (Wretmann, C. \&Macy, R., 2016, U.S Department of Education report, 2010, BlackmonB, 2010). Social work researchers must participate in the development of technology effectiveness, and develop guidelines related to the use of technology. Improving the use of technology in practice and education is the responsibility of social work educators and practitioners.

This integration is recommended by the National Association of Social Workers (NASW, 2005) and later stated as imperative for the profession in the next decade by the NASW in its annual report (NASW, 2010). The implementation of this imperative is not occurring as quickly in the profession of social work (Blackmon, 2012), increasing research and development will make it possible.

Effective integration of technology is possible but requires clear guidelines to facilitate the appropriate use of technology in macro interventions and other social justice activities. Clear guidelines dictate using the appropriate and effective technology in a purposeful method not just using "technology for technology". Avoiding the inappropriate use of technology require users to consider not only the tool, the tools impact upon the populations served, security of the tools, the availability and accessibility of the tools to the population being served. Knowing the potential impact of expanding advocacy efforts with accessibility and availability of technology makes it a top priority not only for the helpers but their clients. Implementing this priority includes assessing the adequacy of technology accessibility to clients and making technological resources available is not optional in today's world. Technology availability and accessibility is a requirement for all clients and their helpers, especially when we collaborate with clients as partners in making social change. Currently, providing accessibility to technology require social workers to realize empowerment means availability of technology to their clients.

Availability means it is necessary to integrate technology into every community centers and social service organization through the creation "hotspots" and hardware at these locations. Creating these change opportunities through accessibility permit clients to learn about their situation from diverse viewpoints. These diverse viewpoints include using technology to organize or registering to vote on line. Imagine if groups collaborated and start a campaign to register individuals online. These examples, suggest the power of technology and it's potential to bring about change.

\section{Description of Approach}

This article describes community practices courses with assignments to expand student knowledge about larger societal conditions and the impact of these conditions upon their clients. 
These social conditions are often the cause of many micro problems experienced by their clients. Instead social work students learn that conditions such as unemployment are underemployment caused by discriminatory employment practices create challenges for groups of persons. Underemployment caused by societal discrimination creates poverty that is not their fault but embedded in society and its organizational structures. For example, corporate practices of hiring from the inside where the current employees do not have any persons of color on staff or running advertisements but never selecting from diverse pools is the reason they are unemployed or underemployed. Students learn to examine the larger conditions that impact the day to day lives of their clients versus personal causes.

The community practice course described in this article integrated the use of technology into the course by using the blackboard Learning Management System, researching social conditions using the internet to locate library databases, and creating interventions using varied technology. These and other type of activities in the course provided students with the opportunity to learn more about cause advocacy combined with technology. This article describes three community practice courses involving a total of 58 students. The focus of the article is to examine student's use of technology involving the integration of technology into advocacy strategies in the course entitled Advanced Community Practice. The course trains students to engage in social change efforts to address social conditions within designated communities impacted by these conditions s. Overview of Course the course was formatted to educate students using a progressive methodranging from basic to complex. Additionally the skills taught are all are connected to course objectives. The assignments are designed to implement course objectives. Student assignmentsare evaluated for compliance with assignment guidelines and rubrics that reflect the expectations of the course and professor. The course outcomeswere measured by the course objectives as achieved by the student completion of assignments..

Students in the course are assigned reading materials around the definitions of advocacy and social change, the difference between individual interventions and macro interventions to change the conditions or address public issues (Longres, 2000 p9).

\section{The Approach}

The initial assignments engage students in basic activities designed to develop the necessary fundamental skills and knowledge needed to assess the impact large systems are having upon the lives of their clients. In the course students have learned the various forces such as economic, social, and political impact clients by creating secondary troubles(Longres, 2000 p52) Making the connection between these forces and the presenting problems is a skills requiring critical thinking to increasinly more complicated situations presented by clients and the communities they live.

Assignment One They learns to understand the concepts of the macro theories and how to apply them to the condition they identify for this assignment. There are a number of ways to assess communities such as the theories suggested in (Krist-Ashman , 2014 p. 337- 375. It is necessary to identify theories that have been identified as appropriate for their use with social conditions ((Weiss). They learn that the theory used to identify conditions is based on the theories assumptions about the environment and the causes of the conditions. Therefore, it is important to analyze the theory. Students may use a variety of frameworks to understand the theory. Once they identify the theory they must ask if the theory is functional, its assumptions, is it appropriate for the population and condition they are assessing (Rogers, 2016 p. 31).

In the Assignment Two, the second assignment, students define advocacy and social change using a set of questions designed to assist them in critically thinking about concepts of social justice and social change. The following questions are examples of the questions provided:

1. What is social justice and social change?

2. Identify current conditions that are the result of or perpetrated by injustice and inequities.

3. What are the available interventions that may be used with clients? What are the theoretical frameworks involved in each intervention.

4. Do the (proposed) interventions address private issues versus public issues or both?

5. Which interventions address the social conditions experienced by the client sometimes called "public issues" and how do they differ from interventions that focus on individual issues?

6. What changes are largely made by the organization using interventions to address public issues, and those made addressing private issues. Are the social conditions changed for the client? 


\section{What did you learn from doing this assignment?}

They are instructed to personally answer the questions provided by the instructor. They are then directed to conduct an individual interview with a current social work practitioner using the same questions. They then compare their answers to the practitioners. This individual may be their field instructor. If the person is the field instructor, this activity will generate discussions with the field instructor about social justice change within the organization and the methods being used to bring about changes in policies and practice.

Part B of Assignment 2 students analyze the information gathered in the interview and discussions with the practitioner. The students analyze the interventions described by the practitioner they interviewed and compare this information to the responses the student made in the beginning of assignment 2.

Assignment three (3) is the development of change strategies using current technology to solve the condition they identified. In order to accomplish this they must now integrate what they were previously lerned about the condition, what needs to be changed, the vehicles for change (Sheafor \& Horejsi, 2012, p. 88).

They then are required to develop technological strategies to address the conditions identified and apply technological mediums to intervene.The technology integration into the interventions demonstrates a higher level of learning because the integration is a progression of information and knowledge development to creative expression of the same concepts (Blooms, 2006). They students started this assignment by studying others who had used technology to bring about change. Students may further their learning by reaching out to other social workers and identify the strategies used by others to bring about change.

The integration of technology is not just the use of the product, but the process. In the $21^{\text {st }}$ century, social workers must accept the challenge to utilize all of the tools available to them. Social work educators must challenge social work students to pursue new and effective change strategies that partner with the latest technological advances. An ongoing assignment that used technology is describing what they learned on the learning management system. The learning management system allowed the instructor to incorporate discussion boards that allowed students to articulate in writing what they are learning, learned, share their viewpoints with peers and the instructor. In the discussion board students are provided questions to encourage them to probe the concepts with questions designed to enhance student knowledge about the concepts for the course including those posed by peers. The interaction on the discussion board with their peers is structured to avoid "me too" responses. Specific guidelines were provided and posted on Blackboard, the learning management system.

The collaboration activity on Blackboard proposes to increase the student's skills in conceptualizing the materials, conveying it to others, critically evaluate and demonstrate their understanding of what they are reading when communicating their understanding to once the condition and the change strategy students determine the compatibility of the change strategy with the appropriate technology. Identifying the type of technology is important to social workers and student social workers if they are to expand the types of interventions and strategies that go beyond local levels. Accepting this challenge will permit them to develop effective skills bring about social change. Meeting this challenge will require that social worker incorporates the latest technological advances that will inform, education and organize the most people effectively (Tetloff et al., 2014; Young, 2014). Students in social work education learn that, as a member of the social work profession, they have the responsibility and the duty to bring about change. However, the way to achieve this task within social work practice varies and using technology to do so is limited in the literature. This article will begin to address the gap in the information about the use of technology in bringing about change by describing how students address social conditions and their use of technology when engaging in community practice focusing on change.

\section{Description of the Results}

The course assignment challenged students to identify and address a community issue or condition and attempt to change its impact on client populations. The students began the assignment by identifying the condition to be studied by assessing community needs. They then examined each assessment involving peers in the class and community group members. The students identified a variety of conditions, such as HIV/AIDS, bias against persons with persistent mental illness, lack of dental services for the elderly, foster care children and youth violence. The level of sophistication of each proposed project was varied. This variation may be attributed to skill level, knowledge, and motivation of each student. 
The students developed a plan for addressing the condition selected as a group. They then developed project proposals based on the plan that included a plan of action, description of the condition, and identifying strategies that they would utilize to bring about change. The students provided literature support from the assigned reading materials to support their use of the various strategies. The students used their initial proposal to guide the implementation. The students presented the results during the last class sessions. A description of the conditions address, the technological strategy used, and the number of students using each type of technological strategy is provided below:

Example of Student Activities

\begin{tabular}{|l|l|l|}
\hline Conditions/Issues & Technology Strategy & Number Using this Method* \\
\hline $\begin{array}{l}\text { AIDS in Black Church } \\
\text { Community }\end{array}$ & $\begin{array}{l}\text { A Facebook page with a forum to debate the } \\
\text { issue with a purpose of challenging distortions } \\
\text { about HIV/AIDS }\end{array}$ & $\begin{array}{l}\text { Ten students used the Facebook forum } \\
\text { as a method of informing others about } \\
\text { the perception of AIDS in the Black } \\
\text { Church others used PowerPoint } \\
\text { presentations }\end{array}$ \\
\hline $\begin{array}{l}\text { Youth Violence. Student } \\
\text { violence, domestic violence }\end{array}$ & $\begin{array}{l}\text { Developed a link from a civil rights website to } \\
\text { discuss the issues, included games, simulations } \\
\text { and scenarios. Independent website. Updated e- } \\
\text { mail addresses and created mail merge features. }\end{array}$ & $\begin{array}{l}\text { Six students developed web pages, } 2 \\
\text { developed a web page and linked from } \\
\text { community organization. Designed } \\
\text { mail merge lists for civil rights org }\end{array}$ \\
\hline Fental Health discrimination & $\begin{array}{l}\text { PowerPoint presentations to discuss the } \\
\text { challenges faced by persons with persistent } \\
\text { mental illness. }\end{array}$ & $\begin{array}{l}\text { 24 students used PowerPoint as a } \\
\text { method of getting the message out } \\
\text { about their condition. }\end{array}$ \\
\hline $\begin{array}{l}\text { Developed PowerPoint and video presentations } \\
\text { illustrating a foster care condition occurring } \\
\text { when placements are disrupted. Students used } \\
\text { publisher to develop fact sheets. Twitter } \\
\text { account was established. Some students } \\
\text { focused on finding funding for luggage for } \\
\text { foster care children. Creating a "Go Fund Me" } \\
\text { page is the latest acquisition students use. }\end{array}$ & $\begin{array}{l}\text { community practice courses addressing } \\
\text { foster care }\end{array}$ \\
\hline
\end{tabular}

*Some students used multiple mediums to address single condition

The identification of issues was left to the students based on their interests, along with their past and current experiences. Permitting them to make the selection offered them an opportunity to expand their knowledge about a topic that they had some familiarity and interest. Simultaneously, the students learned to conduct electronic research through the use of multiple databases to acquire new and enhanced knowledge about the topic. Conducting research to identify statistics and literature discussing the condition or issues they selected was important.

Based on student feedback and review of the course, more technology was integrated as a regular part of the course offering. The courses incorporated virtual chats, such as blogs and discussion boards, to expand the classroom dialogs about social justice and other related issues. One discussion board question asked students "Can social workers use the internet and other web based mediums to assist in the delivery of client services?" This question directed students to explore with each other the current use of the internet and expand their views of technology through discussions with others. In addition, students are encouraged to expand classroom activities by engaging in real world activities in the community. For example, students connect with community organizations and provide services that are not connected to their practicum. In one semester, a group of students developed a web page with simulations, games, and information directed at young people as a part of an outreach campaign sponsored by a civil rights organization.

Social work advocacy requires a number of interventions if it is to be effective. Those interventions must include the new mediums through technology. The use of new technology mediums in advocacy expands the repertoire of social workers, and in so doing, they become more familiar with them as they are with the use of DVD's or email. The student social workers changed their perceptions regarding the use of letters of support, letter writing campaigns, and telephone calls to congress when they realized that these traditional methods could use an upgrade to electronic tools. Sending letters electronically to develop a constituency and, in turn, contact the appropriate policy makers faster and enlarge the group of supporters. 
A secondary effect of the assignment led to ongoing partnerships with community organizations. These partnerships resulted in the promotion of change by students in partnership with the organizations. Bringing about system and social change require collaborations, therefore, the communities benefited from the activities in these courses. Social work is in the initial stages of these collaborations. However, they should take the model of business that is morphing from the competitive model to collaboration (Tapscott, D., 2010)

Expanding the use of technology into social work courses need to be researched to determine its effectiveness in training students how to use social change strategies using technology. Furthermore, the more we use it may have the result of attracting the social work researchers to partner with social workers who are involved in social and policy change. It is important to reinforce the results obtained from our practice experiences that are qualitative descriptions of the integration of technology through the replication of these efforts to determine how much students learned from each media integration. Technology is not the new; however we must integrate it and measure its effectiveness in increasing student learning. The integration will not only expand our views about technology, but its many possibilities to change education and social work practice.

\section{Conclusion}

The use of emerging technologies use in social work advocacy needs further research. However, electronic advocacy is here to stay. The use of technology into education is becoming more commonplace in some professions; it has become an acceptable tool for enhancing learning. The inclusion of technology into the social workers education toolkit is varied and almost nonexistent in interventions directed toward social change and the empowerment of clients. However, the opportunity exists to engage in interventions that will challenge old paradigms about education of social workers and others in the helping professions. Transforming views about the way we learning and teach should occur and figuring out ways to develop partnerships with students so that they take responsibility for learning, therefore changing the focus to the middle of the room. Developing tool kit that contain videos, web pages, virtual forums, Facebook, Twitter, PowerPoint, and podcasting will transform the use of these mediums as tools to change the way social work educators and practitioners teach and practice.

\section{Recommendations}

Attaining social justice using technology is an opportunity to establish collaboration between clients and social workers. This partnership forms the basis for building a base for change using the internet as common denominator. Technology is an equalizer when social workers realize the power of technology and the many ways it can be used to empower clients like the student social workers in this course are able to gain knowledge about their condition, engage in self advocacy, and find support. For example, virtual forums such as blogs and discussion boards, and social media, such as Facebook, provide clients the opportunity to speak up about their conditions, desires for change, and find others who are doing something about it. The challenge is to get ahead of technology by using social media in courses and assignments to benefit the vulnerable, oppressed, and those needing support in their efforts to growth and change.

Social work education using technology in each course will train students as advocates who make a difference in the conditions clients' experience. When faculty uses technology in their classrooms they are modeling its use. Developing assignments using social media will demonstrate the expansion of traditional interventions that excite client and student. For example, training social workers and their clients about history, civil rights, resources online, and how information found on the information highway is power. Clients then realize that they have the power to change their own condition.

\section{References}

Birkenmaier, Berg-Weger, M., \& Dewees, M.P., $3^{\text {rd }}$ ed. (2014) The Practice of Generalist, Routledge, New York, New York

Blackmon, B (2012). With All Deliberate Speed: Using Technology in social work Education, Journal of Evidence Based Social Work

Brueggemann, William G. (2006), The Practice of Macro Social Work $3^{\text {rd }}$ ed.,Brooks/Cole, Belmont, CA

Council on Social Work Education. $(2015,2008)$ Educational Policy and Accreditation Standards.Alexandria, VA, Glickman, M.D., (2007) Social Work in the $21^{\text {st }}$ Century: an introduction to socialwelfare, social issues, and the profession, Sage Publication, Thousand Oaks, CA. 
Hardcastle, David A., \& Patricia Powers. Community Practice: Theories and Skills for Social Workers, $3^{\text {rd }}$ ed. (2010) New York, New York, Oxford University Press.

Hardina, Donna, Interpersonal Social Work Skills for Community Practice (2013) New York, New York, Springer Publishing Company, LLC.

Hick, S.E., McNutt, J.G., (2002). Advocacy, Activism, and the Internet: community organization and social policy, Lyceum Books, Inc, Chicago, Illinois.

Hoffer, R., (2006). Advocacy Practice for Social Justice, Lyceum Books, Inc., Chicago, Illinois.

Jansson, B., Becoming an Effective Policy Advocate: From Policy Practice to Social Justice $6^{\text {th }}$ ed (2011) Belmont, California, Thomson Brooks Cole

Kirst-Ashman, (2013). Human Behavior in the Macro Social Environment $4^{\text {th }}$ ed.,Brookes and Cole, Cengage Learning, Belmont, CA.

Kirst-Ashman, Karen K. and Hull, Grafton H., Generalist Practice with Organizations and Communities (2006), Belmont, California, Thomson Brooks/Cole.

Lauri Goldkind, Lea Wolf \&James Jones (2016). Late Adapter? How Social Workers Acquire Knowledge and Skills about Technology Tools, Journal of Technology in Human Services, V 34: 4 338-358.

Longres, J.F., (2000). Human Behavior and the Social Environment ( $3^{\text {rd }}$ ed Peacock publishers). Itasca, IL.

National Association for Social Worker Code of Ethics. (2015). Washington, DC.

National Association for Social Worker Code of Ethics. (2008). Washington, DC.

NASW Institutional Racism and the social work Profession, A Call to Action, (2005), Washington, DC.

National Association for Social Workers Annual Report (2010), Washington, D.C.

Netting, F.E., Kettner, P., \& McMurty, S. $4^{\text {th }}$ ed. (2008) Social Work Macro Practice, Pearson, Boston, Mass

Regan, J.A., \& Freddolino, P. (2016) Integrating Technology into the Social Work Curriculum, Journal of Social Work Education, $v$.

Rogers, A. T. (2013). Human behavior in the social environment, Routledge, New York, NY.

Rothman, J., Erlich, J., Tropman, J., Strategies of Community Intervention. $6^{\text {th }}$ ed, (2001)

Understanding American Communities" United States, Thomson; Brook/Cole,

Sheafor, B. W., Horejsi, C. R., \& Horejsi, G. A. (2012). Techniques and guidelines for social work practice $9^{\text {th }}$ ed., Allyn and Bacon, Boston, MA.

Tetloff, M., Hitchcock, L., Battista, A., \& Lowry, D. (2014). Multimodal Composition and Social Justice: Videos as a Tool of Advocacy in Social Work

PedagogyJournal of Technology in Human Services, 32(1/2), 22-38. doi:10.1080/15228835.2013.857284

United States Department of Education, Office of planning, Education, and Policy

Development (2010). Evaluation of Evidence-based Practice in Online Learning: A Meta-Analysis and Review of Online Learning Studies, D.C.

Weil, Marie, Reisch, Michael, and Ohmer, Mary L. 2013), The Handbook of Community $\quad$ Practice $2^{\text {nd }}$ ed. Sage Publications, Inc

Wretman, Christopher, \& Macy, Rebecca. (2016). Social Work Education: A Systemic Review, Journal of Social Work Education, 34, 409-421

Young, J. (2014). Policy: Exploring and Evaluating the use of iPads in a Social Welfare

Policy Course. Journal of Technology in Human Services, 32(1/2), 39-53. doi:10.1080/15228835.2013.860366 